\title{
Particulate polyaryletherketones with amine end functionalisation by a Friedel Crafts dispersion polymerisation
}

Kaylie J. Smith, Ian D. H. Towle, James F. Pratte, Robin K Maskell and Mark G. Moloney

Department of Chemistry, Chemistry Research Laboratory, The University of Oxford, 12 Mansfield Road, Oxford. OX1 3TA.

Ketonex Ltd, Leafield Technical Centre, Langley, Witney, Oxfordshire, OX29 9EF.

Cytec Industries Inc. Woodland Park, New Jersey, United States of America.

mark.moloney@chem.ox.ac.uk

Amine end-capped PAEKs are available by a dispersion process using a protection-deprotection strategy with an end-capping aminoaromatic derivative which adds no further steps to the dispersion polymerisation method. A model compound approach was employed to demonstrate successful amine attachment to the polymer, together with its compatibility and suitability within the polymer system. This approach was successful for linear and trifunctional versions. Scale-up of the PAEK dispersion synthesis was achieved to $300 \mathrm{~g}$ batches. Amine end-capped PEKK with 100:0, 80:20, 60:40 T:I ratios, along with branched PEKK and PEKK-imide copolymers were synthesised. Mechanical analysis confirmed a substantial increase in fracture toughness on incorporation of the functionalised PEKK particles in an epoxy resin laminate when compared to non-functionalised PEKK particles.

\section{Introduction}

Epoxy resins are one of the thermoset frameworks commonly used as the matrices in high performance composites for engineering applications. The starting materials for the epoxy resins are linear, epoxide rich "prepreg" oligomers, and a wide variety of these oligomers are available which vary in structural components including backbone, functionality, epoxide density and molecular weight, depending on the application of the material ${ }^{1}$. Curing of the oligomers by a range of Lewis acids and bases, but most commonly amines, results in a chemically crosslinked structure via ring-opening reactions at the epoxides. The major disadvantage of epoxy resins is that they are usually brittle, and therefore the improvement of their toughness has been researched widely. ${ }^{1-3}$ Many methods of toughening have been developed, the most common being the incorporation of fibrous fillers, such as carbon fibre and glass fibre, or toughening particles, and these include rubbers, ${ }^{4}$ silica, ${ }^{5}$ and microvoids, ${ }^{6}$ together with thermoplastics. Significant commercial interest exists in the composites sector for the production of high performance thermoplastic particles to act as toughening agents in thermoset resins, and specifically polyetherimides (PEIs), ${ }^{7}$ polyarylether ketones (PAEK)s, and polyarylether sulfones (PAESs), ${ }^{8}$ since the dispersion of thermoplastic particles in thermoset resins acts to maintain the modulus of the material whilst increasing fracture toughness. ${ }^{8,9}$ It is thought that each thermoplastic particle acts as an energy absorption point which impedes 
fracture propagation through the thermoset matrix. ${ }^{10}$ Attempts have been made to toughen epoxy resins with PES by the exploitation of its favourable solubility parameters, ${ }^{11}$ because PES is soluble in uncured epoxy resin but precipitates as fine droplets and forms solid particles when the epoxy is cured, producing the particles in situ. Although this system does impart toughness, PES is often amorphous and does not exhibit the required solvent resistance in application. By comparison, whilst PAEKs are semi-crystalline and impart solvent resistance, they are insoluble in uncured epoxy resin and therefore this phase separation approach is not possible. An alternative to the phase separation method is the dispersion of non-epoxy soluble thermoplastic particulates into the resin, but since these particulates need to be produced by cryogenic grinding of pellets, it is an extremely expensive process due to the energy cost of cooling. In addition, the particles produced are irregular in shape and size, whereas ideally particles should be as close to spherical as possible and have particle diameters in the range of $10-50 \mu \mathrm{m}$ to obtain the optimum mechanical properties. ${ }^{12}$ A further issue is that many thermoplastics do not withstand the high temperatures of around $150{ }^{\circ} \mathrm{C}$ required for the curing of thermoset resins. Moreover, if the thermoplastic particles could be chemically bound to the epoxy matrix, the fracture toughness of the composite would be increased further, since this would fuse the particle-polymer interface. ${ }^{9}$ This ought be achievable if appropriate amine endcapping functionality could be introduced onto the polymer particle, which might be expected to chemically bind to the epoxy resin during curing. The synthesis of such amine end-capped PAEK oligomers and polymers for epoxy toughening has been described. Bennett ${ }^{13}$ reported a one-pot synthesis of amine endcapped oligomers by the nucleophilic reaction of 4,4'-difluorobenzophenone bearing a substituted hydroquinone with aminophenol. However, low molecular weight oligomers were produced with poor amine termination efficiency due to competitive ketimine formation, and a modified two-step synthesis where the aminophenol was added during the second step was more successful. In this approach, ketimine formation appears to be problematic, ${ }^{14}$ but has been avoided by the nucleophilic reaction of a hydroxy- terminated PEK oligomer with a halonitroaromatic end-capper, ${ }^{15}$ which was subsequently reduced to introduce amine functionality. In addition, halogen-terminated oligomers have been reacted with ammonia with a copper (I) chloride catalyst to achieve amine functionality. We report here the synthesis of amine end-capped, near spherical, particulate PEKK by an adaptation our recently reported dispersion process ${ }^{16}$ which is suitable for linear PEKKs, branched PEKKs and PEKK-EIEIE copolymers.

\section{Results and Discussion}

Two approaches were examined for the production of a range of PAEKs with terminal amine functionality by the dispersion process. The first was the direct end-capping of the polymers with 4phenoxyaniline 1a i.e. an unprotected amine, while the second was end-capping with a monomer with an protected amine, including the acetyl end-capper $\mathrm{N}$-(4-phenoxyphenyl)acetamide (EC-A, 1b) and the trifluoroacetyl end-capper 2,2,2-trifluoro- $N$-(4-phenoxyphenyl)acetamide (EC-F, 1c) (Scheme 1). A model study was initially conducted to assess the compatibility of the end-cappers in the polymerisation system, and end-capper attachment and deprotection. The simplest method to achieve amine functionalisation by direct end-capping would be by the addition of a species to the end of a polymer chain which incorporates 
amine functionality. In a preliminary study, 4-phenoxyaniline was reacted with terephthaloyl chloride (TPC) or isophthaloyl chloride (IPC) in a 2:1 stoichiometric ratio using aluminium chloride catalyst, but neither of the desired ketones were obtained, and the corresponding amides N1,N4-bis(4phenoxyphenyl)terephthalamide 2a and N1,N3-bis(4-phenoxyphenyl)isophthalamide 2b (Scheme 1) were obtained instead. ${ }^{17}$ This, along with the known reaction of aminophenol with ketones on the polymer chain to form ketimines, ${ }^{14}$ clearly indicated that a protecting group for the amine would be necessary to ensure clean reaction, and the direct end-capping route was discounted.

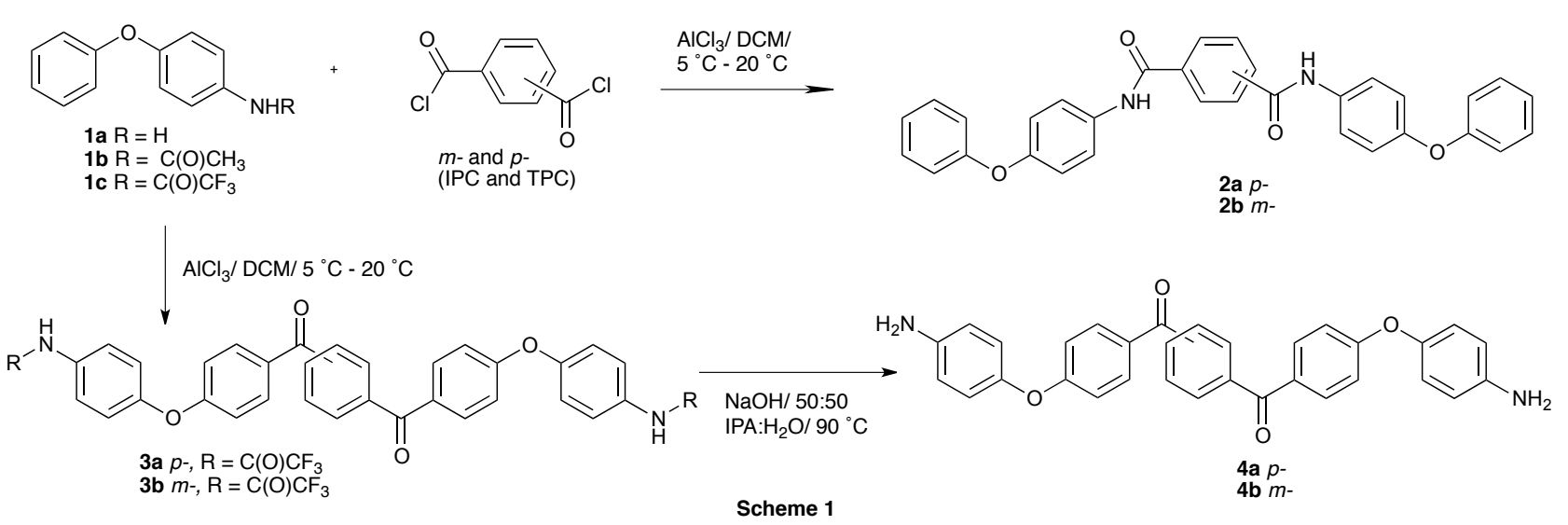

A protected end-capper approach was therefore investigated, in which the amine of the 4phenoxyaniline was protected with either acetyl or trifluoroacetyl groups. EC-A 1b and EC-F 1c (Scheme 1) were synthesised by standard methodology, and both resulted in high purity product in good yield. Since post-polymerisation deprotection of both end-capping molecules would be required following successful addition to the polymer chain to produce terminal amine end functionality, acid and base deprotection was examined. The removal of the acetamide protecting group is reported by treatment in aqueous solution at $\mathrm{pH}$ $>12$ or $\mathrm{pH}<1$, at $100{ }^{\circ} \mathrm{C}$ but the trifluoroacetamide protecting group is more sensitive to base, and hydrolysis occurs by treatment in aqueous solution at $\mathrm{pH}>10$ or $\mathrm{pH}<1$, at $100{ }^{\circ} \mathrm{C}$. ${ }^{18}$ When acid and base deprotection of EC-A 1b and EC-F 1c were tested experimentally, successful deprotection of EC-A 1b could only be achieved under alkaline reflux for 1.5 hours conditions, but base hydrolysis of EC-F 1c was successful on heating the compound at $80{ }^{\circ} \mathrm{C}$, as well as at reflux, for one hour. Despite the additional expense of the trifluoroacetyl system, it was chosen as the preferred protecting group, since its deprotection only requires small modification of the standard polymer workup procedure i.e. a washing step using sodium hydroxide rather than ammonia. However, one concern relating to the use of using sodium hydroxide for the deprotection step was the risk of introducing sodium ions into the polymer, which if not removed successfully during workup, would greatly decrease melt stability of the polymer. ${ }^{19,20}$

Since it was expected that definitive amine analysis could not be easily achieved from amine endcapped PEKK polymer due to the extremely low concentration of chain ends in comparison to the bulk polymer, a model compound approach was required establish end-capper attachment in the polymer system. Linear model compounds were produced by the $\mathrm{AlCl}_{3}$-catalysed Friedel-Crafts acylation reaction of a phthaloyl dichloride (either TPC and IPC) and EC-F 1c in a 1:2 stoichiometric ratio in DCM (Scheme 1), to 
give TPC-EC 3a and IPC-EC 3b respectively, which both exhibited the expected spectroscopic data. Deprotection of these model compounds under alkaline conditions (sodium hydroxide, $\mathrm{pH}$ 13) required a mixed solvent system of 2:1 volume ratio water : isopropyl alcohol for solubility, giving $\mathbf{4 a}$ and $\mathbf{4 b}$ (melting points of $221.1^{\circ} \mathrm{C}$ (lit. ${ }^{21} 226.0-230.0{ }^{\circ} \mathrm{C}$ ) and $165.2{ }^{\circ} \mathrm{C}$ (lit. ${ }^{21} 161.5-164{ }^{\circ} \mathrm{C}$ ) respectively). NMR analysis indicated a small proportion of protected species remaining in the deprotected samples, but full deprotection could be achieved by increasing the reaction time to $1.5 \mathrm{~h}$. This outcome suggested that the use of EC-F 1c would provide a successful route to achieve terminal amine functionality in the polymerisation system, using post-polymerisation deprotection during polymer workup and with a sodium hydroxide washing step replacing the ammonia-washing step.

In addition to amine end-capped linear PEKK, it was of interest to develop a branched amine endcapped PEKK by the incorporation of the trifunctional monomer 1,3,5-benzenetricarbonyl chloride (TRI) 5 into the monomer feed. With the incorporation of this monomer, there was a statistical probability that EC-F 1c would react with the trifunctional acid chloride rather than TPC or IPC. Thus, a trifunctional model compound was synthesised by reaction of TRI 5 with EC-F $1 \mathbf{c}$ in a 1:3 stoichiometric ratio to form TRI-EC 6a (Scheme 2). TRI-EC was subjected to base deprotection with $\mathrm{NaOH}$ at $\mathrm{pH} 13$, in the same manner as the linear model compounds, to form TRI-EC-D $\mathbf{6 b}$, whose structure was confirmed by FT-IR, NMR spectroscopy, DSC and mass spectroscopy. This success indicated that end-capping by EC-F 1c, and its subsequent deprotection, should be compatible with the polymerisation system by incorporation of TRI 5 into the monomer feed.

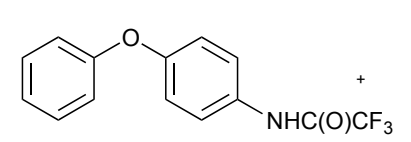

$1 c$

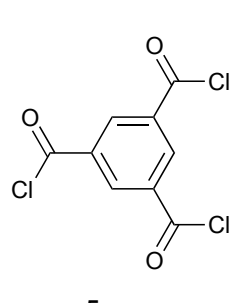

5

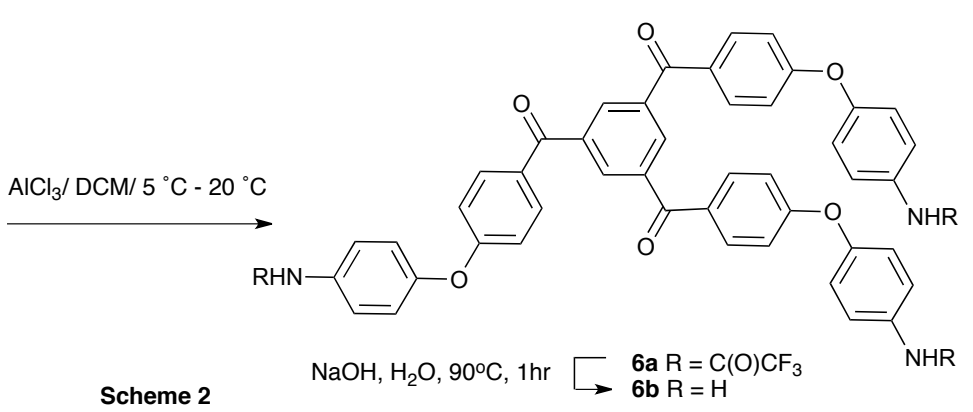

On the basis of the success of these preliminary studies, the protected end-capper method for amine functionalisation was therefore extended to the dispersion polymerisation system. Amine end-capped PEKK was produced by the standard dispersion process ${ }^{22}$, replacing the usual benzoyl chloride end-capper in the monomer feed with EC-F 1c (Scheme 3). ${ }^{12}{ }^{23}$ The use of EC-F 1c requires the acid chloride to be in excess to ensure terminal attachment. A small scale polymerisation of 100:0 PEKK was therefore carried out with large acid chloride excess and with EC-F replacing the benzoyl chloride in the monomer feed to confirm the addition of the end-cappers in the polymerisation system and the subsequent deprotection during basic workup. The large excess resulted in the production of oligomers with a high proportion of amine end groups, whose presence was confirmed by a characteristic broad peak at $9.52 \mathrm{ppm}$ of the $\mathrm{N}-\mathrm{H}$ proton in the ${ }^{1} \mathrm{H}$ NMR spectrum. The protected end-capping method was then used to produce a range of PAEKs, scaled up to a five litre reactor with batch size $300 \mathrm{~g}$ of polymer, to include linear PEKKs (100:0, 80:20, 60:40) or branched PEKK (Scheme 3) and PEKK-imide copolymer (prepared analogously to the literature method ${ }^{17}$ ) 
(Scheme 4) by appropriate modification of the monomer feed. The polymerisations were carried out with a large enough acid chloride excess to result in a large end group concentration whilst maintaining a high enough molecular weight to impart desirable mechanical properties (full details are included in the SI).

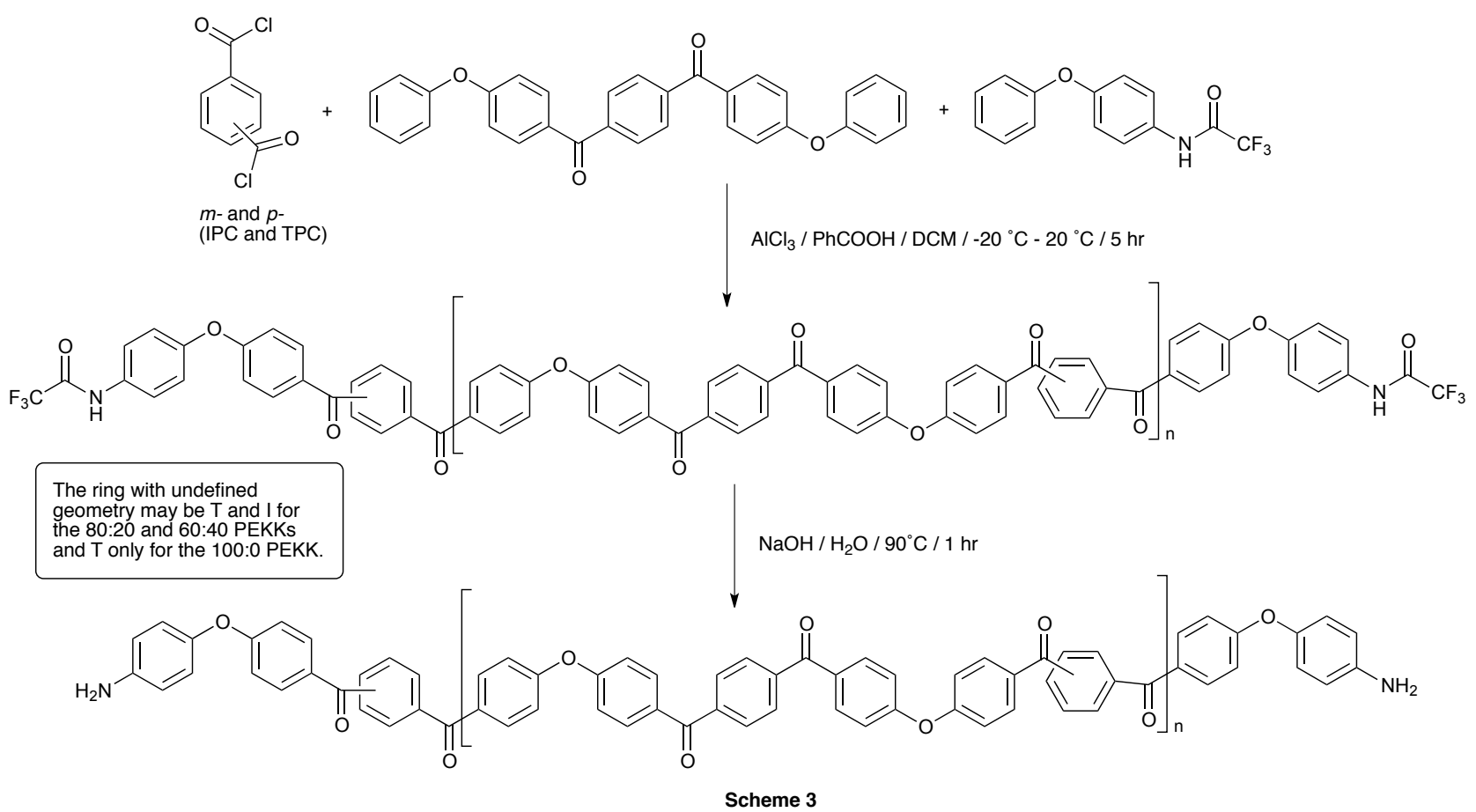

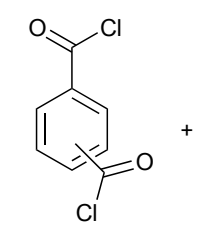
$m$ - and $p-$
(IPC and TPC) $m-$ and $p-$
(IPC and TPC)<smiles>[O][GeH2]O</smiles><smiles>O=C(c1ccc(Oc2ccccc2)cc1)c1ccc(Oc2ccccc2)cc1</smiles><smiles>c1ccccc1</smiles><smiles>O=C(Nc1ccc(Oc2ccccc2)cc1)C(F)(F)F</smiles>

$5 c$

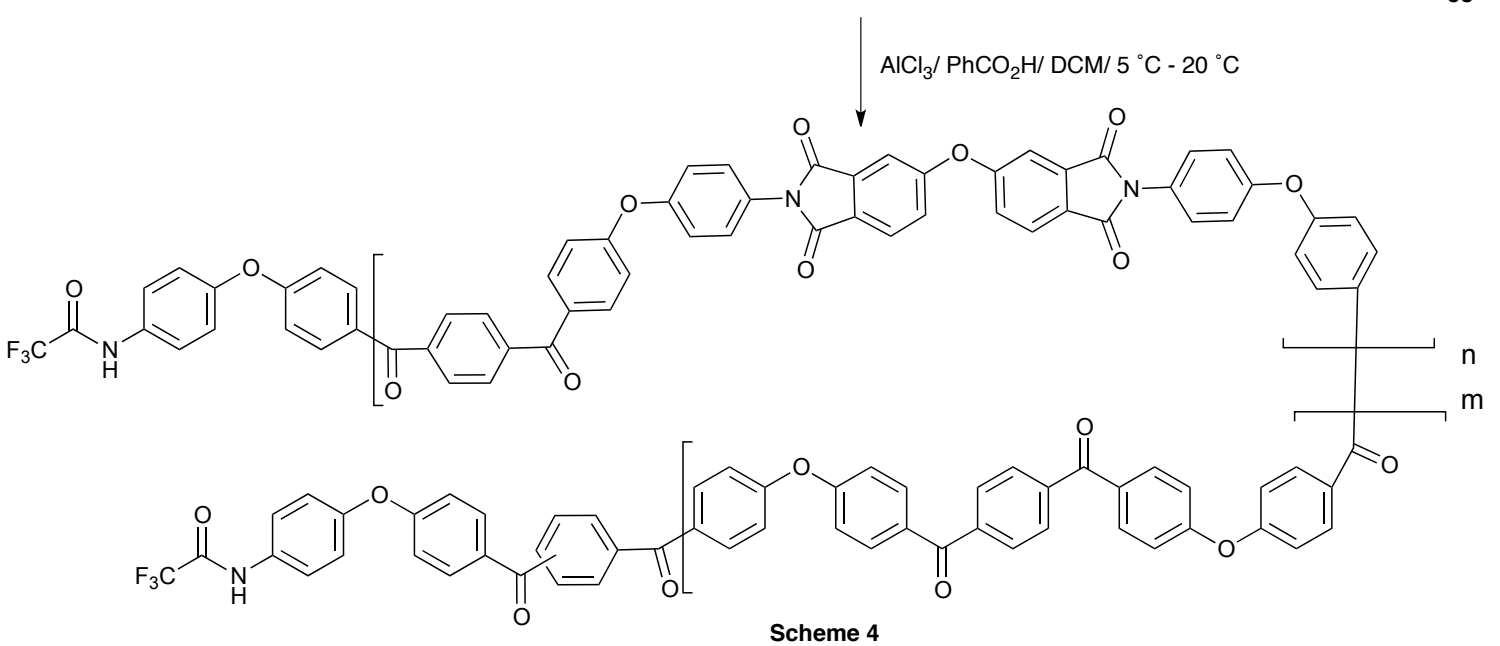

Quantitative combustion analysis was carried out on 6 replicates of amine end-capped 100:0 PEKK, and this confirmed the presence of nitrogen, albeit with differences between the theoretical and calculated values (Table 1), and this discrepancy is thought to be due to incomplete combustion of the PAEKs which 
are known to have good fire resistance, low combustion and a high char residue. ${ }^{24,25}$ FT-IR spectroscopy was carried out on the solid 100:0 PEKK which confirmed both the presence of the expected carbonyl bands, along two weak absorption bands at $3500-3300 \mathrm{~cm}^{-1}$, characteristic of primary amines, ${ }^{26}$ and which have been previously observed for amine terminated PEEK oligomers. ${ }^{14}$

\begin{tabular}{|l|c|c|c|}
\hline \% & $\mathbf{C}$ & $\mathbf{H}$ & $\mathbf{N}$ \\
\hline Theoretical & 75.93 & 4.03 & 0.23 \\
\hline $100: 0(1)$ & 77.97 & 3.93 & 0.44 \\
\hline $100: 0(2)$ & 78.27 & 4.01 & - \\
\hline $100: 0(3)^{*}$ & 77.80 & 3.92 & 0.67 \\
\hline $100: 0(4)^{*}$ & 77.69 & 3.93 & 0.67 \\
\hline $100: 0(5)^{*}$ & 78.14 & 3.91 & 0.67 \\
\hline $100: 0(6)^{*}$ & 78.00 & 3.95 & 0.62 \\
\hline \multicolumn{2}{|c}{ *Tungsten oxide catalyst included } \\
\hline
\end{tabular}

Table 1. Theoretical and calculated values for $\% \mathrm{C}, \mathrm{H}, \mathrm{N}$ combustion analysis for 100:0 PEKK with and without tungsten oxide catalyst.

Qualitative analysis with ninhydrin was used to confirm the presence of amine groups, ${ }^{27}$ a positive result being the generation of purple colour; the test was carried out in DCM to swell the polymer particles, rendering the amine groups accessible. Successful colouration was observed for each of the amine endcapped PAEKs, whereas the non-amine end-capped samples remained white (Table 2). The colour development took several hours, and this suggests that the amine groups are dispersed through the particles and not located only on the surface. This successfully demonstrated the incorporation of terminal amine functionality, but it was also necessary to determine if the functionalisation affected the bulk polymer properties. The IVs of the linear and branched PEKK polymers were measured and found to be in the region of $0.46-0.63 \mathrm{dL} \cdot \mathrm{g}^{-1}$ (Table 2), which is in the expected range of a PEKK polymerisation run at this excess.

\begin{tabular}{|l|c|c|c|c|}
\hline \multirow{2}{*}{ Polymer } & \multicolumn{3}{|c|}{ Ninhydrin test } & \multirow{2}{*}{ IV/ dL.g $\mathbf{~}^{-1}$} \\
\cline { 2 - 4 } PEKK 100:0 & Image & Colour & Result & \\
\hline PEKK 90:10 & & White & Negative & 0.88 \\
\hline PEKK-NH 100:0 & & White & Negative & 0.80 \\
\hline PEKK-NH $80: 20$ & & Pink & Positive & 0.63 \\
\hline PEKK-NH $\mathrm{NH}_{2}$ 60:40 & & Purple & Positive & 0.50 \\
\hline $\begin{array}{l}\text { PEKK-NH } 100: 0, \\
\text { branched 5\% }\end{array}$ & & $\begin{array}{c}\text { Purple } \\
\text { purple }\end{array}$ & Positive & 0.46 \\
\hline PEKK-EIEIE-NH & & $\begin{array}{c}\text { Dark } \\
\text { purple }\end{array}$ & Positive & 0.24 \\
\hline
\end{tabular}


Table 2. Colour development in ninhydrin tests for the presence of amine end-capping on the PAEKs, and Inherent Viscosity (IV) measurements of amine end-capped PEKKs, carried out in concentrated sulphuric acid at $25^{\circ} \mathrm{C}$

\begin{tabular}{|c|c|c|c|c|}
\hline & 100:0 PEKK & 80:20 РЕКК & 60:40 PEKK & $\begin{array}{l}\text { Branched } \\
\text { PEKK }\end{array}$ \\
\hline $\begin{array}{l}\text { Heating 1 } \\
\mathrm{T}_{\mathrm{g}} /{ }^{\circ} \mathrm{C} \\
\Delta \mathrm{Cp}^{*} / \mathrm{Jg}^{-1} \mathrm{~K}^{-1}\end{array}$ & $\begin{array}{l}- \\
-\end{array}$ & $\begin{array}{l}- \\
-\end{array}$ & - & - \\
\hline $\begin{array}{l}\mathrm{T}_{\mathrm{m}} /{ }^{\circ} \mathrm{C} \\
\Delta \mathrm{H} / \mathrm{Jg}^{-1}\end{array}$ & $\begin{array}{c}380.1 \\
-47.98\end{array}$ & $\begin{array}{c}351.7,362.5 \\
\quad-49.52\end{array}$ & $\begin{array}{c}272.7,306.2 \\
-17.18\end{array}$ & $\begin{array}{c}345.2,358.6 \\
\quad-40.32\end{array}$ \\
\hline $\begin{array}{l}\text { Heating } 2 \\
\mathrm{~T}_{\mathrm{g}} /{ }^{\circ} \mathrm{C} \\
\Delta \mathrm{Cp}^{*} / \mathrm{Jg}^{-1} \mathrm{~K}^{-1}\end{array}$ & $\begin{array}{l}177.7 \\
0.078\end{array}$ & $\begin{array}{l}160.4 \\
0.067\end{array}$ & $\begin{array}{l}164.8 \\
0.219\end{array}$ & $\begin{array}{l}168.1 \\
0.121\end{array}$ \\
\hline $\begin{array}{l}\mathrm{T}_{\mathrm{m}} /{ }^{\circ} \mathrm{C} \\
\Delta \mathrm{H} / \mathrm{Jg}^{-1}\end{array}$ & $\begin{array}{c}354.4 \\
-15.13\end{array}$ & $\begin{array}{c}347.3 \\
-23.74\end{array}$ & $\begin{array}{l}- \\
-\end{array}$ & $\begin{array}{c}328.9 \\
-17.57\end{array}$ \\
\hline $\begin{array}{l}\text { Cooling 1 } \\
\mathrm{T}_{\mathrm{g}} /{ }^{\circ} \mathrm{C} \\
\Delta \mathrm{Cp}^{*} / \mathrm{Jg}^{-1} \mathrm{~K}^{-1}\end{array}$ & $\begin{array}{l}- \\
-\end{array}$ & $\begin{array}{l}- \\
-\end{array}$ & $\begin{array}{l}151.2 \\
0.021\end{array}$ & $\begin{array}{l}- \\
-\end{array}$ \\
\hline $\begin{array}{l}\mathrm{T}_{\mathrm{d}} /{ }^{\circ} \mathrm{C} \\
\Delta \mathrm{H} / \mathrm{Jg}^{-1}\end{array}$ & $\begin{array}{l}289.9 \\
17.42\end{array}$ & $\begin{array}{l}274.2 \\
29.15\end{array}$ & - & $\begin{array}{l}234.9 \\
21.89\end{array}$ \\
\hline $\begin{array}{l}\text { Cooling 2 } \\
\mathrm{T}_{\mathrm{g}} /{ }^{\circ} \mathrm{C} \\
\Delta \mathrm{Cp}^{*} / \mathrm{Jg}^{-1} \mathrm{~K}^{-1}\end{array}$ & $\begin{array}{l}165.1 \\
0.020\end{array}$ & $\begin{array}{l}- \\
-\end{array}$ & $\begin{array}{l}152.9 \\
0.001\end{array}$ & $\begin{array}{l}164.2 \\
0.105\end{array}$ \\
\hline $\begin{array}{l}\mathrm{T}_{\mathrm{d}} /{ }^{\circ} \mathrm{C} \\
\Delta \mathrm{H} / \mathrm{Jg}^{-1}\end{array}$ & $\begin{array}{l}288.8 \\
8.057\end{array}$ & $\begin{array}{l}259.8 \\
25.11\end{array}$ & $\begin{array}{l}- \\
-\end{array}$ & $\begin{array}{l}261.4 \\
9.315 \\
\end{array}$ \\
\hline
\end{tabular}

Table 3. DSC data for the amine end-capped PEKK based polymers, including two heating and cooling cycles 90 - 400 ${ }^{\circ} \mathrm{C}$ at $20{ }^{\circ} \mathrm{C} \cdot \mathrm{min}^{-1}$ and $400-90{ }^{\circ} \mathrm{C}$ at $10{ }^{\circ} \mathrm{C} \cdot \mathrm{min}^{-1}$. The DSC trace for the imide copolymer is unclear and thermal transitions could not be assigned

The thermal properties of the bulk amine end-capped polymers differ from the non-amine endcapped versions (Table 3), with the $T_{g}, T_{m}$ and $T_{c}$ values for all of the amine end-capped polymers being lower than those of the non end-capped analogues, ${ }^{16}$ although each of these parameters still remain in the region expected from PAEK copolymers. The DSC trace for the imide copolymer was unclear and thermal transitions could not be assigned. SEM analysis ${ }^{12}$ confirmed the size and morphology of the particles (Figure 1), with the particle diameter increasing in the order 100:0 PEKK, 80:20 PEKK and branched PEKK from approximately 40 to $90 \mu \mathrm{m}$. The particles were substantially spherical, with grooves in the comparatively smooth exteriors. However, the particle diameter of the PEKK-imide copolymer ranged from $60-90 \mu \mathrm{m}$, and the particles had an irregular, porous appearance, possibly suggesting agglomerates of smaller particles. The 60:40 PEKK was in the form of elongated particles of around $500 \mu \mathrm{m}$ in length and $100 \mu \mathrm{m}$ in width, with a porous interior. However, the particle size was not fully controlled, and all of the samples contained a proportion of particles outside the size ranges stated. 

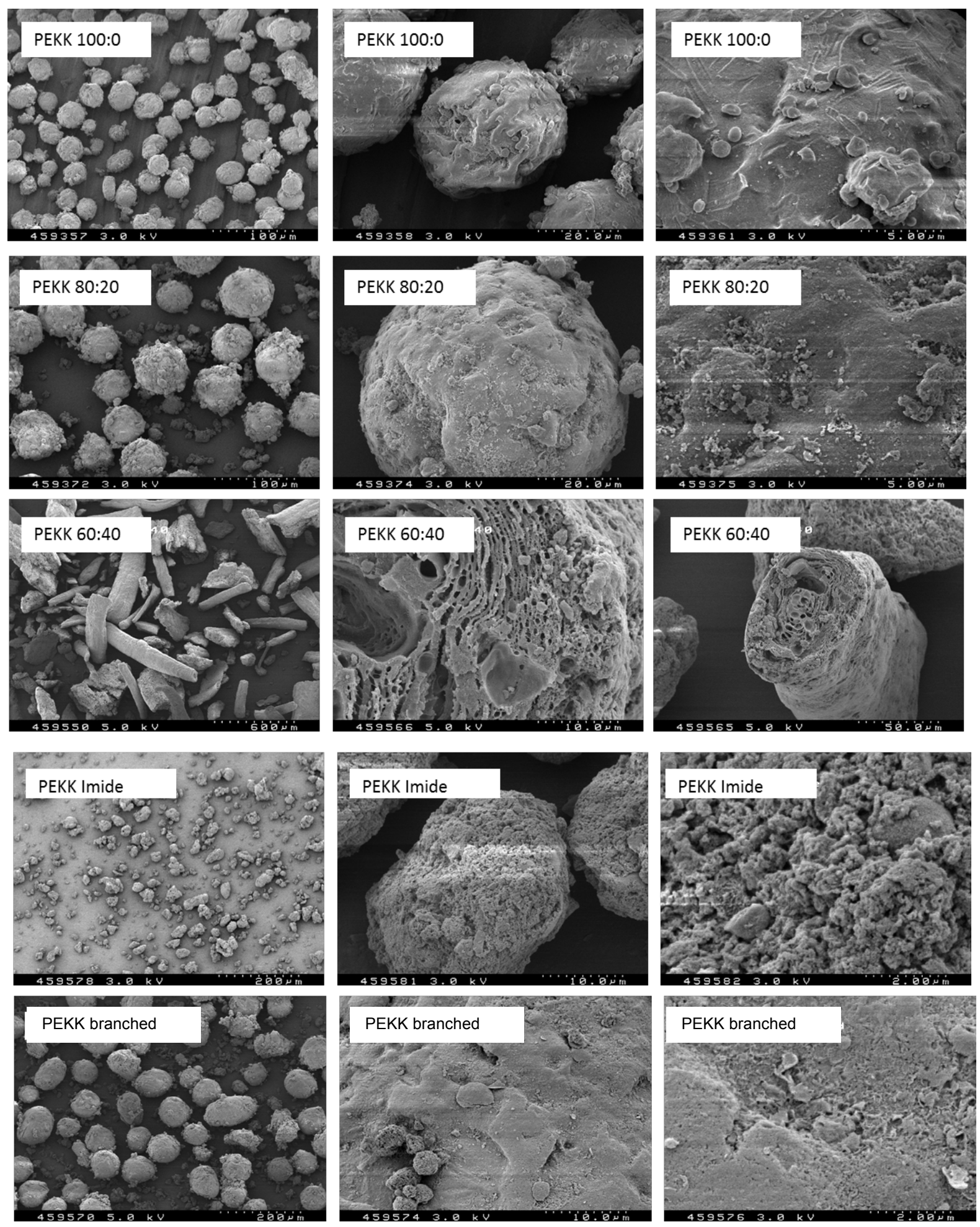

Figure 1. SEM images of the amine end-capped 100:0 PEKK, 80:20 PEKK, 60:40 PEKK, PEKK-imide and branched PEKK at three levels of magnification (Permission from Cytec Industries to reproduce these images from patent application US 2015/0337183 A1 is gratefully acknowledged ${ }^{31}$ ).

The amine functionalised PAEK particles were incorporated into composite multi-layer laminates to evaluate their toughening potential, ${ }^{12}$ and dispersed in the resin-rich, inter-laminar region between carbon fibre toughened epoxy resin layers (Figure 2). 


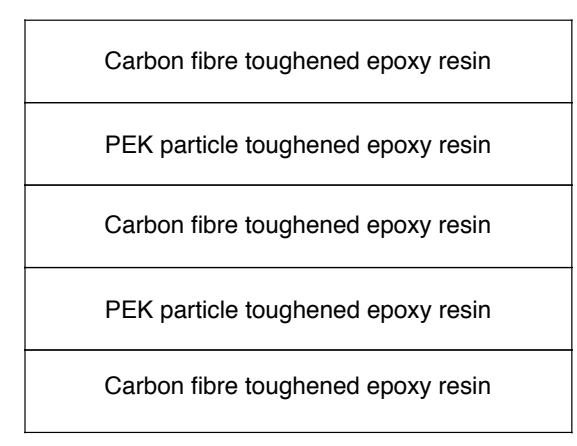

(a) Diagrammatic representation of laminate structure

\begin{tabular}{|c|c|}
\hline PEKK & $\mathrm{G}_{\mathrm{IIC}} / \mathrm{kJ} \cdot \mathrm{m}^{-2}$ \\
\hline Unfunctionalised & 1.339 \\
\hline Functionalised & 2.474 \\
\hline
\end{tabular}

(average of two measurements)

(b) Fracture toughness $\left(G_{I I C}\right)$ data for cured epoxy resin test panels with incorporated non-functionalised and functionalised PEKK particles ${ }^{12}$

Figure 2: Assessment of mechanical strength of test laminates.

The incorporation of functionalised PEKK particles into epoxy resin test panels showed approximate doubling of fracture toughness, $\mathrm{G}_{\text {IIC }}$, from 1.3 to $2.5 \mathrm{KJ} . \mathrm{m}^{-2}$ for two independent sample measurements when compared to those prepared with non-functionalised PEKK particles (Figure 2). SEM analysis was carried out on the fracture surface of an epoxy resin test panel incorporated with functionalised PEKK particles, and this showed that fracture propagation caused both particle pull-out, to leave a crater in the surface, and particle fracture-through, where part of the particle remains attached to the surface (Figure 3), and this is clear evidence that the particles were chemically bonded to the epoxy resin. Since the thermoplastic toughening particles increase the fracture toughness and damage tolerance of the composite laminate, these materials are likely to be suitable for applications which require load bearing and impact resistant structures.

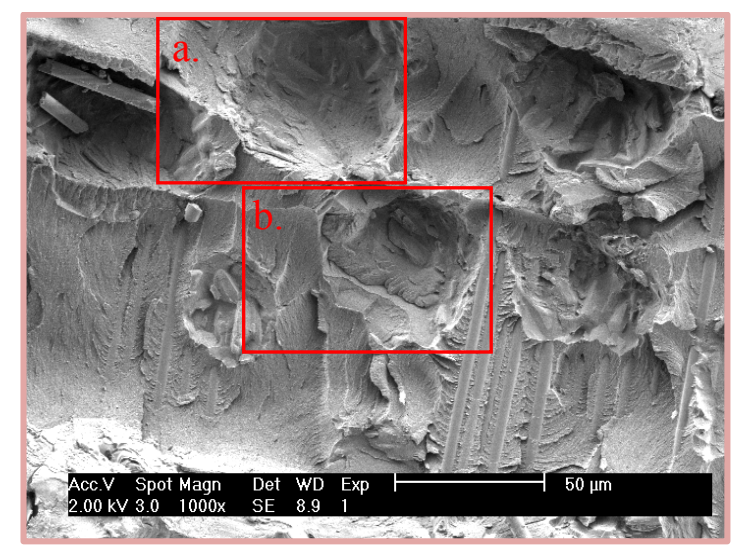

Figure 3. SEM image of a fracture surface of an epoxy resin text panel with incorporated functionalised PEKK particles, to show a. particle pull-out and b. particle fracture-through (Permission from Cytec Industries to reproduce these images from patent application US 2015/0337183 A1 is gratefully acknowledged ${ }^{31}$ ).

\section{Conclusion}

We have shown that amine end-capped polymers are available by a dispersion polymerisation process, and lead to the formation of homogeneous particles; incorporation into test substrates indicates enhance mechanical properties, indicative of covalent cross linking of particle into the epoxy polymeric resin. This approach offers the possibility of a cost effective route to the enhancement of mechanical properties of epoxy resin materials. 


\section{Acknowledgements}

KJS gratefully acknowledges the award of an 1851 Royal Commission Industrial Fellowship.

\section{Experimental}

\section{Instrumentation}

Inherent viscosity (IV) measurements were carried out using Poulten Selfe \& Lee glass Ostwald viscometers, size D, in a Townson and Mercer E270 viscometer bath. Measurements were carried out in a solvent of concentrated sulfuric acid at $25{ }^{\circ} \mathrm{C}$. Differential scanning calorimetry (DSC) data were recorded on a Netzsch DSC 200 F3 Maia $^{\circledR}$ instrument. Data was recorded using pierced lid aluminium crucibles in a nitrogen atmosphere. Cooling was achieved via a forced air system above $20{ }^{\circ} \mathrm{C}$, or by liquid nitrogen cooling for lower temperatures and fast cooling rates. Data was analysed using Proteus ${ }^{\circledR}$ software. Melting point and mol\% purity were calculated using the standard protocol in Proteus ${ }^{\circledR}$ software. Low resolution mass spectra were recorded on a Fisons Platform spectrometer using electrospray ionisation (ESI) or a Fisons AutoSpec-oaTof spectrometer using electron impact ionisation (EI) or field ionisation (FI). The $\mathrm{m} / \mathrm{z}$ values of major peaks are reported in Daltons. High resolution mass spectra (HRMS) were recorded on a Bruker microTof spectrometer (ESI). ${ }^{1} \mathrm{H}$ NMR spectra were recorded on Bruker AVN400 (400 MHz), and DRX500 $(500 \mathrm{MHz})$ spectrometers. Chemical shifts $\left(\delta_{\mathrm{H}}\right)$ are reported in parts per million $(\mathrm{ppm})$ and are referenced to the residual protonated solvent peak. The abbreviations used to describe multiplicities are as follows: $\mathrm{s}$ (singlet), d (doublet), dd (double doublet), t (triplet), q (quartet), m (multiplet) and br (broad). In most cases, first order multiplicities are reported only. Coupling constants $(J)$ are given in Hertz $(\mathrm{Hz})$. Two dimensional COSY (correlation spectroscopy) were obtained on a Bruker AVN400 or DRX500 spectrometer. ${ }^{13} \mathrm{C}$ NMR spectra were recorded on a Bruker AVN400 spectrometer at $100.6 \mathrm{MHz}$ or a Bruker DRX500 spectrometer at $125.8 \mathrm{MHz}$ with proton decoupling. . 19F NMR spectra were recorded on a Bruker AVN400 spectrometer at $376.6 \mathrm{MHz}$. Chemical shifts $(\delta \mathrm{F})$ are reported in parts per million (ppm) and are referenced to $\mathrm{CFCl}_{3}$. Chemical shifts $\left(\delta_{\mathrm{C}}\right)$ are reported in parts per million $(\mathrm{ppm})$ and are referenced to the residual protonated solvent peak. Assignment was aided by the use of DEPT editing and edited HSQC, performed on either AVN400 or DRX500 spectrometers.

\section{Reagents and solvents}

1,4-Bis(4-phenoxybenzoyl)benzene) (polymerisation grade) (EKKE) and 5,5'-oxybis(2-(4phenoxyphenyl)isoindoline-1,3-dione) (EIEIE) may be obtained by the literature procedure. ${ }^{28}$ Terephthaloyl chloride (99+\%) (TPC), isophthaloyl chloride (98\%) (IPC), benzoic acid (99\%, extra pure), aluminium chloride (99 \%, extra pure, anhydrous), benzoyl chloride (98+ \%), 4-phenoxyaniline (97\%), methylcyclohexane (99\%), acetic anhydride (98+\%), trifluoroacetic anhydride (99+\%), $N, N$ Dimethylacetamide (99\%) and magnesium sulfate (97\%) were obtained from Acros Organics. 1,3,5Benzenetricarbonyl chloride (98+\%) was obtained from Alfa Aesar. Decolourising charcoal was obtained from Sigma Aldrich. Sodium hydrogen carbonate (99+\%) and sodium hydroxide pellets 
$(97+\%)$ were obtained from Fisher Scientific. Dichloromethane (DCM) (99.5\%), methanol (99.9\%) and acetone (99.5\%) were obtained from APC Pure. All reagents and solvents were used as received.

\section{Attempted direct end-capping for the synthesis of TPC-P.}

$\operatorname{DCM}(50 \mathrm{ml})$ was added to a conical flask with a magnetic stirrer, and cooled in ice to $5{ }^{\circ} \mathrm{C}$. Aluminium chloride $(5.03 \mathrm{~g}, 37.7 \mathrm{mmol})$ was added, with swirling, together with the DCM washings. Between each of the subsequent additions and washings, the mixture was cooled in ice to below room temperature with swirling. Next, 4-phenoxyaniline $(2.74 \mathrm{~g}, 14.8 \mathrm{mmol})$ was added, followed by TPC (1.50 g, $7.39 \mathrm{mmol})$, including the DCM washings $(100 \mathrm{ml}$ total). The dark green mixture was stirred at room temperature for 1.5 hours. The reaction mixture was poured into stirring iced water, yielding a beige precipitate in the DCM layer. This mixture was heated on a hotplate to remove the DCM. The beige precipitate was isolated by filtration, was washed with deionised water $(3 \times 50 \mathrm{ml})$ and dried in an air oven. The beige product was recrystallised in dimethylacetamide, washed with acetone and dried in an air oven, yielding $2 \mathbf{a}$ as a grey solid (2.87 g), m.p $332.5^{\circ} \mathrm{C}$ (lit. ${ }^{17}$ m.p. $328.4-329.5^{\circ} \mathrm{C}$ ).

\section{Attempted direct end-capping for synthesis of IPC-P}

DCM $(50 \mathrm{ml})$ was added to a conical flask with a magnetic stirrer, and cooled in ice to $5{ }^{\circ} \mathrm{C}$. Aluminium chloride (5.04 g, $37.7 \mathrm{mmol}$ ) was added, with swirling, together with the DCM washings. Between each of the subsequent additions and washings, the mixture was cooled in ice to below room temperature with swirling. Next, 4-phenoxyaniline $(2.73 \mathrm{~g}, 14.7 \mathrm{mmol})$ was added, followed by TPC (1.50 g, $7.39 \mathrm{mmol})$, including the DCM washings (100 $\mathrm{ml}$ total). The dark purple mixture was stirred at room temperature for 1.5 hours. The reaction mixture was poured into stirring iced water, yielding a beige precipitate in the DCM layer. This mixture was heated on a hotplate to remove the DCM. The beige precipitate was isolated by filtration, was washed with deionised water $(3 \times 50 \mathrm{ml})$ and dried in an air oven. The beige product was recrystallised in dimethylacetamide, washed with acetone and dried in an air oven, yielding $\mathbf{2} \mathbf{b}$ as a grey solid (2.93 g), m.p. $274.3{ }^{\circ} \mathrm{C}$ (lit. ${ }^{17}$ m.p. $\left.268.5-269.7^{\circ} \mathrm{C}\right)$.

\section{$N$-(4-phenoxyphenyl)acetamide (EC-A) 1b}

4-Phenoxyaniline (20.4 g, $0.110 \mathrm{~mol})$ was dissolved in DCM (200 ml) with stirring. To the very dark brown solution was added decolourising charcoal $(3 \mathrm{~g})$ and the resulting suspension stirred for 15 minutes. The suspension was filtered through a Soxhlet thimble into a conical flask. On drainage of the thimble, further DCM $(200 \mathrm{ml})$ was filtered into the conical flask via the thimble. After cooling the conical flask in an ice bath to $5{ }^{\circ} \mathrm{C}$, acetic anhydride $\left(11.1 \mathrm{~cm}^{3}, 0.109 \mathrm{~mol}\right)$ was added to the aniline solution. An exothermic reaction occurred, raising the temperature to $30{ }^{\circ} \mathrm{C}$. After stirring for 30 minutes the solution was poured into water $(1000 \mathrm{ml})$ and stirred for 10 minutes. Stirring was stopped before decanting the majority of the aqueous layer. Water $(500 \mathrm{ml})$ was replaced. A saturated solution of sodium hydrogen carbonate was added to the water/ DCM mixture, accompanied by effervescence. Addition was continued until the $\mathrm{pH}$ of the mixture was below $\mathrm{pH}$ 7. At this point, the organic layer was extracted using a separating funnel. This layer 
was dried by the addition of anhydrous magnesium sulphate $(5 \mathrm{~g})$. Decolourising charcoal $(3 \mathrm{~g})$ was added and, after stirring for 15 minutes, the suspension was filtered through a fresh Soxhlet thimble, washed through with DCM, resulting in a transparent pale red-brown solution. Methylcyclohexane (300 ml) was added to the solution with heating, removing the DCM and reducing the overall volume to approximately 75 $\mathrm{ml}$ and resulting in the production of pale pink crystals. The solid was recrystallised from methylcyclohexane and EC-A 1b was isolated as a pink crystalline solid (21.0 g, 85\%); purity 99.99 mol\% (DSC); mp $131.2^{\circ} \mathrm{C}$ (lit. ${ }^{29} 130-131{ }^{\circ} \mathrm{C}$ ); $v_{\max } / \mathrm{cm}^{-1} 3286(\mathrm{NH}), 2240-1760$ (aromatic CH), 1699 (CO), 1659 $(\mathrm{NH}), 1545,1842 ; \delta_{\mathrm{H}}\left(400 \mathrm{MHz}, \mathrm{CDCl}_{3}\right) 2.19\left(3 \mathrm{H}, \mathrm{s}, \mathrm{CH}_{3}\right), 6.97-7.01(4 \mathrm{H}, \mathrm{m}, \mathrm{C}(6) H, \mathrm{C}(3) H), 7.11(1 \mathrm{H}, \mathrm{t}, J$ 7.58, C(8)H), $7.34(2 \mathrm{H}, \mathrm{t}, J 7.95, \mathrm{C}(7) H), 7.48(2 \mathrm{H}, \mathrm{d}, J 9.05, \mathrm{C}(2) H), 7.57\left(1 \mathrm{H}\right.$, br. s, NH); $\delta_{\mathrm{C}}(100 \mathrm{MHz}$, $\left.\mathrm{CDCl}_{3}\right) 24.40\left(C(10) \mathrm{H}_{3}\right), 118.47(C(3)), 119.56(C(6)), 121.81(C(8)), 123.12(C(2)), 129.75(C(7)), 133.38$ $(C(1)), \quad 153.53(C(4)), \quad 157.50 \quad(C(5)), \quad 168.47 \quad(C(9) \mathrm{O}) ; \quad m / z \quad\left(\mathrm{ESI}^{+}\right) \quad 250 \quad\left([\mathrm{M}+\mathrm{H}]^{+}\right) ; \quad \mathrm{HRMS} \quad\left(\mathrm{ESI}^{+}\right)$ $\mathrm{C}_{14} \mathrm{H}_{13} \mathrm{NNaO}_{2}^{+},\left([\mathrm{M}+\mathrm{Na}]^{+}\right)$requires 250.0838 found 250.0827 .

\section{2,2,2-Trifluoro- $N$-(4-phenoxyphenyl)acetamide (EC-F) $1 \mathrm{c}$}

4-Phenoxyaniline (15.0 g, $81.1 \mathrm{mmol})$ was dissolved in DCM (200 $\mathrm{ml})$ with stirring. To the very dark brown solution was added decolourising charcoal $(3 \mathrm{~g})$ and the resulting suspension stirred for 15 minutes. The suspension was filtered through a Soxhlet thimble into a conical flask. On drainage of the thimble, further DCM $(200 \mathrm{ml})$ was filtered into the conical flask via the thimble. After cooling the conical flask in an ice bath to $5^{\circ} \mathrm{C}$, trifluoroacetic anhydride $(16.1 \mathrm{~g}, 76.5 \mathrm{mmol})$ was added to the aniline solution. An exothermic reaction occurred, raising the temperature to $35{ }^{\circ} \mathrm{C}$. After stirring for 30 minutes, the solution was poured into water $(1000 \mathrm{ml})$ and stirred for 10 minutes. Stirring was stopped before decanting the majority of the aqueous layer. Water $(500 \mathrm{ml})$ was replaced. A saturated solution of sodium hydrogen carbonate was added to the water/ DCM mixture, accompanied by effervescence. Addition was continued until the $\mathrm{pH}$ of the mixture was below $\mathrm{pH}$ 7. At this point, the organic layer was extracted using a separating funnel. This layer was dried by the addition of anhydrous magnesium sulphate $(5 \mathrm{~g})$. Decolourising charcoal ( $3 \mathrm{~g})$ was added and, after stirring for 15 minutes, the suspension was filtered through a fresh Soxhlet thimble, washed through with DCM, resulting in a transparent pale red-brown solution. Methylcyclohexane (300 ml) was added to the solution with heating, removing the DCM and reducing the overall volume to approximately 75 $\mathrm{ml}$ and resulting in the production of pale pink crystals. The solid was recrystallised from methylcyclohexane, was washed with methanol and EC-F 1c was isolated as a pale pink crystalline solid (19.9 g, 88\%); purity $99.99 \mathrm{~mol} \%$ (DSC); $\mathrm{mp} 114.2{ }^{\circ} \mathrm{C} ; v_{\max } / \mathrm{cm}^{-1} 3284(\mathrm{NH}), 2260-1770$ (aromatic $\mathrm{CH}$ ), $1702(\mathrm{CO}), 1540(\mathrm{NH}), 1148 ; \delta_{\mathrm{H}}\left(400 \mathrm{MHz}, \mathrm{CDCl}_{3}\right)$ 6.91-6.96 (4H, m, C(6)H, C(3)H), 7.27 (2H, t, J 8.07, $\mathrm{C}(7) H), 7.44(2 \mathrm{H}, \mathrm{d}, \mathrm{J} 9.05, \mathrm{C}(2) H), 7.58(1 \mathrm{H}, \mathrm{t}, J 7.05, \mathrm{C}(8) H), 7.91\left(1 \mathrm{H}\right.$, br. s, NH); $\delta_{\mathrm{C}}\left(100 \mathrm{MHz}, \mathrm{CDCl}_{3}\right)$ $115.79\left(\mathrm{q}, C \mathrm{~F}_{3}\right), 119.05(C(6)), 119.36(C(3)), 122.36(C(2)), 123.75(C(8)), 129.92(C(1)), 130.10(C(7))$,

$154.64(C(4)), 155.52(C(9) \mathrm{O}), 156.77(C(4)) ; \delta_{\mathrm{F}}\left(376 \mathrm{MHz}, \mathrm{CDCl}_{3}\right)-75.63\left(\mathrm{CF}_{3}\right) ; \mathrm{m} / z\left(\mathrm{ESI}^{+}\right) 304$ $\left([\mathrm{M}+\mathrm{Na}]^{+}\right)$; HRMS $\left(\mathrm{ESI}^{+}\right) \mathrm{C}_{14} \mathrm{H}_{10} \mathrm{~F}_{3} \mathrm{NNaO}_{2}{ }^{+},\left([\mathrm{M}+\mathrm{Na}]^{+}\right)$requires 304.0556 found 304.0550.

\section{4-Phenoxyaniline by the hydrolysis of EC-F 1c}


A portion of EC-F 1c $(100 \mathrm{mg}, 0.36 \mathrm{mmol})$ was treated with deionised water $(25 \mathrm{ml})$ and isopropyl alcohol ( $25 \mathrm{ml}$ ), and made up to $\mathrm{pH} 13$ with a single sodium hydroxide pellet, which caused EC-F to dissolve. The mixture was heated at $85{ }^{\circ} \mathrm{C}$ for 1.5 hours, during which time a white suspension was produced. The solid was isolated by filtration and, washed with deionised water and dried in an air oven to yield 4phenoxyaniline as a white crystalline solid (47 mg, 71\%), mp $85.1{ }^{\circ} \mathrm{C}\left(1 \mathrm{it} .{ }^{30} 85-86{ }^{\circ} \mathrm{C}\right)$; purity $99.95 \mathrm{~mol} \%$ (DSC); $v_{\max } / \mathrm{cm}^{-1} 3386$ and $3309(\mathrm{NH}), 3224,2250-1740$ (aromatic $\left.\mathrm{CH}\right), 1585(\mathrm{NH}), 1482,1221 ; \delta_{\mathrm{H}}(400$ $\left.\mathrm{MHz}, \mathrm{CDCl}_{3}\right) 3.45\left(2 \mathrm{H}\right.$, br. s, $\left.\mathrm{NH}_{2}\right), 6.60(2 \mathrm{H}, \mathrm{d}, J 8.80, \mathrm{C}(2) H), 6.80(2 \mathrm{H}, \mathrm{d}, J 8.56, \mathrm{C}(3) H), 6.85(2 \mathrm{H}, \mathrm{d}, J$ 7.58, C(26)H), $6.93(1 \mathrm{H}, \mathrm{t}, J 7.34, \mathrm{C}(8) H), 7.17-7.22(2 \mathrm{H}, \mathrm{t}, J 8.0 \mathrm{C}(7) H) ; \delta_{\mathrm{C}}\left(100 \mathrm{MHz}, \mathrm{CDCl}_{3}\right) 116.29$ $(C(2)), 117.25(C(6)), 121.15(C(3)), 122.09(C(8)), 129.55(C(7)), 142.64(C(1)), 148.64(C(4)), 158.91$ $(C(5)) ; m / z\left(\mathrm{ESI}^{+}\right) 186\left([\mathrm{M}+\mathrm{H}]^{+}\right) ; \mathrm{HRMS}\left(\mathrm{ESI}^{+}\right) \mathrm{C}_{12} \mathrm{H}_{12} \mathrm{NO}^{+},\left([\mathrm{M}+\mathrm{H}]^{+}\right)$requires 186.0913 found 186.0906.

\section{Attempted hydrolysis of EC-A $1 \mathrm{~b}$}

A portion of EC-A $(100 \mathrm{mg}, 0.37 \mathrm{mmol})$ was treated with deionised water $(25 \mathrm{ml})$ and IPA $(25 \mathrm{ml})$, and made up to $\mathrm{pH} 13$ with a single sodium hydroxide pellet, which caused EC-A to dissolve. The mixture was heated at $85^{\circ} \mathrm{C}$ for 1.5 hours, during which time a white suspension was produced. The solid was isolated by filtration and, washed with deionised water and dried in an air oven to yield unreacted starting material (80 $\mathrm{mg}, 82 \%)$.

\section{2,2,2-Trifluoro- $N$-(4-(3-(4-(4-(4-(2,2,2-trifluoroacetamido)phenoxy)benzoyl)benzoyl) phenoxy)phenyl)acetamide (TPC-EC) 3a}

DCM $(50 \mathrm{ml})$ was added to a conical flask with a magnetic stirrer, and cooled in ice to $5{ }^{\circ} \mathrm{C}$. Aluminium chloride (5.03 g, $37.7 \mathrm{mmol}$ ) was added, with swirling, together with the DCM washings. Between each of the subsequent additions and washings, the mixture was cooled in ice to below room temperature with swirling. Next, EC-F (4.17 g, $14.8 \mathrm{mmol})$ was added, followed by TPC (1.51 g, $7.44 \mathrm{mmol})$, including the DCM washings (100 ml total). The mixture was stirred at room temperature for 1.5 hours, during which time the orange-brown solution became yellow. The reaction mixture was poured into stirring iced water, yielding a white precipitate in the DCM layer. This mixture was heated on a hotplate to remove the DCM. The cream precipitate TPC-EC was isolated by filtration, was washed with deionised water $(3 \times 50 \mathrm{ml})$ and dried in an air oven. The cream product was recrystallised in dimethylacetamide, washed with acetone and dried in an air oven, yielding TPC-EC 3a as a grey solid (4.72 g, 92\%); mp $325.9{ }^{\circ} \mathrm{C}$; purity $98.85 \mathrm{~mol} \%$ (DSC); $v_{\max } / \mathrm{cm}^{-1} 3275(\mathrm{NH}), 2250-1800$ (aromatic $\mathrm{CH}$ ), $1705(\mathrm{CO}), 1645$ (amide CO), 1517 (aromatic $\mathrm{C}=\mathrm{C}$ ), 1543 $(\mathrm{NH}), 1234(\mathrm{CF}), 1150(\mathrm{PhOPh}) ; \delta_{\mathrm{H}}\left(500 \mathrm{MHz}, \mathrm{CDCl}_{3(\mathrm{TFA})}\right) 7.13(4 \mathrm{H}, \mathrm{d}, J$ 8.83, C(6)H), 7.22 (4H, d, J 8.51, $\mathrm{C}(2) H), 7.63(4 \mathrm{H}, \mathrm{d}, J 8.51, \mathrm{C}(3) H), 7.91-7.93(8 \mathrm{H}, \mathrm{m}, \mathrm{C}(7) H, \mathrm{C}(11) H), 8.56(2 \mathrm{H}, \mathrm{s}, \mathrm{N} H)$; $\delta_{\mathrm{C}}(125 \mathrm{MHz}$, $\left.\mathrm{CDCl}_{\text {(TFA) }}\right)$ 114. $86(C F 3, q), 119.79(C(6) \mathrm{H}), 121.71(C(2) \mathrm{H}), 124.12(C(3) \mathrm{H}), 130.35(C(8)), 130.49$ $(C(11) \mathrm{H}), 134.24(C(7) \mathrm{H}), 140.99(\mathrm{C}(1)), 142.21(C(10)), 154.32(C(4)), 157.56(C \mathrm{~F} 3, \mathrm{q}), 163.69(C(5))$, $200.03(C(9) \mathrm{O})$; HRMS (TOF EI $\left.{ }^{+}\right) \mathrm{C}_{36} \mathrm{H}_{22} \mathrm{~N}_{2} \mathrm{O}_{6} \mathrm{~F}_{6}{ }^{+}$, ([M] $]^{+}$) requires 692.1382 found 692.1423. 
$N, N^{\prime}-(((I s o p h t h a l o y l b i s(3,1-p h e n y l e n e)) b i s(o x y) b i s(4,1-p h e n y l e n e)) b i s(2,2,2-t r i f l u o r o a c e t a m i d e) \quad$ (IPCEC) $3 b$

DCM $(50 \mathrm{ml})$ was added to a conical flask with a magnetic stirrer and cooled in ice to $5{ }^{\circ} \mathrm{C}$. Aluminium chloride (4.84 g, $36.3 \mathrm{mmol}$ ) was added, with swirling, together with the DCM washings. Between each of the subsequent additions and washings, the mixture was cooled in ice to below room temperature with swirling. Next, EC-F (4.16 g, $14.8 \mathrm{mmol})$ was added, followed by TPC (1.51 g, $7.44 \mathrm{mmol})$, including the DCM washings ( $100 \mathrm{ml}$ total). The mixture was stirred at room temperature for 1.5 hours, during which time the orange-brown solution became bright orange. The reaction mixture was poured into stirring iced water, yielding a white precipitate in the DCM layer. This mixture was heated on a hotplate to remove the DCM. The cream precipitate IPC-EC was isolated by filtration, was washed with deionised water $(3 \mathrm{x} 50 \mathrm{ml})$ and dried in an air oven. The cream product was recrystallised in dimethylacetamide, washed with acetone and dried in an air oven, yielding IPC-EC $3 \mathbf{b}$ as a grey solid (4.76 g, 92\%); mp $231.2{ }^{\circ} \mathrm{C}$; purity $97.42 \mathrm{~mol} \%$ (DSC); $v_{\max } / \mathrm{cm}^{-1} 3277(\mathrm{NH}), 2200-1850$ (aromatic CH), 1705 (CO), 1651 (amide CO), 1595 (aromatic $\mathrm{C}=\mathrm{C}), 1543(\mathrm{NH}), 1494,1228(\mathrm{CF}), 1150(\mathrm{PhOPh}) ; \delta_{\mathrm{H}}\left(500 \mathrm{MHz}, \mathrm{CDCl}_{3(\mathrm{TFA})}\right) 7.08(4 \mathrm{H}, \mathrm{d}, J$ 8.83, C(3)H), $7.17(4 \mathrm{H}, \mathrm{d}, J$ 8.83, C(2)H), $7.62(4 \mathrm{H}, \mathrm{d}, J 9.14, \mathrm{C}(7) H), 7.73(1 \mathrm{H}, \mathrm{t}, \mathrm{C}(13) H), 7.87(4 \mathrm{H}, \mathrm{d}, \mathrm{J} 8.83, \mathrm{C}(2) H)$ $8.06(2 \mathrm{H}, \mathrm{dd}, \mathrm{C}(12) H), 8.11(1 \mathrm{H}, \mathrm{s}, \mathrm{C}(11) H), 8.50(2 \mathrm{H}, \mathrm{s}, \mathrm{N} H)$; $\delta_{\mathrm{C}}\left(125 \mathrm{MHz}, \mathrm{CDCl}_{3(\mathrm{TFA})}\right) 114.90(C \mathrm{~F} 3, \mathrm{q})$, $117.94(C(6) \mathrm{H}), 121.67(C(2) \mathrm{H}), 123.89(C(3) \mathrm{H}), 124.60(C(1)), 129.57(C(13) \mathrm{H}), 130.71(C(8)), 131.32$ $(C(11) \mathrm{H}), 134.02(C(7) \mathrm{H}), 134.85(C(12) \mathrm{H}), 137.69(C(10)), 154.06(C(4)), 156.95(C \mathrm{~F} 3, \mathrm{q}), 163.33(C(5))$, $198.83(C(9) \mathrm{O})$; HRMS (TOF EI $\left.{ }^{+}\right) \mathrm{C}_{36} \mathrm{H}_{22} \mathrm{~N}_{2} \mathrm{O}_{6} \mathrm{~F}_{6}{ }^{+},\left([\mathrm{M}]^{+}\right)$requires 692.1382 found 692.1420.

\section{(4-(3-(4-Aminophenoxy)benzoyl)phenyl)(4-(4-aminophenoxy)phenyl)methanone (TPC-EC-D) 4a by}

\section{the deprotection of TPC-EC 3a}

A portion of TPC-EC 3a (130 mg, $0.188 \mathrm{mmol}$ was treated with deionised water $(25 \mathrm{ml})$ and IPA (25 ml), and made up to $\mathrm{pH} 13$ with a single sodium hydroxide pellet, which caused TPC-EC to dissolve. The mixture was heated at $85{ }^{\circ} \mathrm{C}$ for 1.5 hours, during which time a cream suspension was produced. The solid was isolated by filtration, washed with deionised water and dried in an air oven to yield TPC-EC-D $4 \mathbf{a}$ as a beige crystalline solid $(76 \mathrm{mg}, 85 \%)$; $\mathrm{mp} 199.5{ }^{\circ} \mathrm{C}$ (lit. ${ }^{21} 226-230{ }^{\circ} \mathrm{C}$ ); purity $97.63 \mathrm{~mol} \%$ (DSC); $v_{\max } / \mathrm{cm}^{-1} 3377$ and $3310(\mathrm{NH}), 2150-1760$ (aromatic $\mathrm{CH}$ ), $1643(\mathrm{CO}), 1595$ (aromatic $\mathrm{C}=\mathrm{C}$ ), 1506, $1306\left(\mathrm{NH}_{2}\right), 1328$ $(\mathrm{PhOPh}), 1153 ; \delta_{\mathrm{H}}\left(500 \mathrm{MHz}, \mathrm{CDCl}_{3}\right) \delta_{\mathrm{H}}\left(500 \mathrm{MHz}, \mathrm{CDCl}_{3}\right) 7.14(4 \mathrm{H}, \mathrm{d}, J$ 8.83, C(6)H), $7.26(4 \mathrm{H}, \mathrm{d}, J$ 8.51,

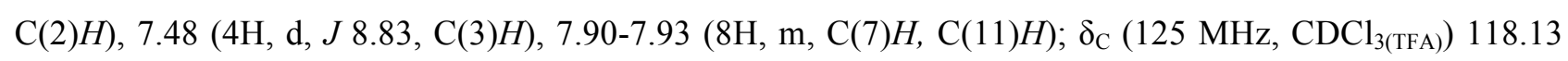
$(C(6) \mathrm{H}), 121.60(C(2) \mathrm{H}), 124.56(C(3) \mathrm{H}), 130.05(C(11) \mathrm{H}), 130.78(C(8)), 133.74(C(7) \mathrm{H}), 140.46(C(1))$, $153.86(C(10)), 156.81(C(4)), 168.20(C(5)), 199.42(C(9) \mathrm{O}) ; \mathrm{HRMS}\left(\mathrm{TOF} \mathrm{EI}^{+}\right) \mathrm{C}_{32} \mathrm{H}_{24} \mathrm{~N}_{2} \mathrm{O}_{4}{ }^{+},\left([\mathrm{M}]^{+}\right)$ requires 500.1736 found 500.1734 .

\section{1,3-Phenylenebis((3-(4-aminophenoxy)phenyl)methanone (IPC-EC-D) $4 \mathrm{~b}$ by the deprotection of IPC- EC 3b}

A portion of IPC-EC $3 \mathbf{b}(113 \mathrm{mg}, 0.164 \mathrm{mmol})$ was treated with deionised water $(25 \mathrm{ml})$ and IPA $(25 \mathrm{ml})$, and made up to $\mathrm{pH} 13$ with a single sodium hydroxide pellet, which caused IPC-EC to dissolve. The mixture 
was heated at $85{ }^{\circ} \mathrm{C}$ for 1.5 hours, during which time a white suspension was produced. The solid was isolated by filtration, washed with deionised water and dried in an air oven to yield IPC-EC-D $\mathbf{4 b}$ as a white crystalline solid (62 mg, 80\%); mp $165.2{ }^{\circ} \mathrm{C}$ (lit. ${ }^{21} 161.5-164.0{ }^{\circ} \mathrm{C}$ ); purity $98.74 \mathrm{~mol} \%$ (DSC); $v_{\max } / \mathrm{cm}^{-1}$ 3449 and $3368(\mathrm{NH}), 2150-1780$ (aromatic $\mathrm{CH}), 1643(\mathrm{CO}), 1595$ (aromatic $\mathrm{C}=\mathrm{C}), 1495,1305\left(\mathrm{NH}_{2}\right), 1240$ $(\mathrm{PhOPh}), 1155 ; \delta_{\mathrm{H}}\left(500 \mathrm{MHz}, \mathrm{CDCl}_{3(\mathrm{TFA})}\right) 7.13(4 \mathrm{H}, \mathrm{d}, J 8.83, \mathrm{C}(3) H), 7.25(4 \mathrm{H}, \mathrm{d}, J$ 8.83, C(6)H), 7.47 (4H, $\mathrm{d}, J 9.14, \mathrm{C}(7) H), 7.75(1 \mathrm{H}, \mathrm{t}, J 7.72, \mathrm{C}(13) H), 7.90(4 \mathrm{H}, \mathrm{d}, J 8.83, \mathrm{C}(2) H), 8.08(2 \mathrm{H}, \mathrm{dd}, J 7.88,1.58$, $\mathrm{C}(12) H), 8.15(1 \mathrm{H}, \mathrm{s}, \mathrm{C}(11) H) ; \delta_{\mathrm{C}}\left(125 \mathrm{MHz}, \mathrm{CDCl}_{3(\mathrm{TFA})}\right) 118.20(C(6) \mathrm{H}), 121.59(C(2) \mathrm{H}), 124.59(C(3) \mathrm{H})$, $124.78(C(1)), 129.18(C(13) \mathrm{H}), 130.89(C(8)), 131.39(C(11) \mathrm{H}), 133.63(C(7) \mathrm{H}), 134.63(C(12) \mathrm{H}), 137.01$ $(C(10)), 156.82(C(4)), 162.61(C(5)), 198.96(C(9) \mathrm{O})$; HRMS (TOF $\left.\mathrm{EI}^{+}\right) \mathrm{C}_{32} \mathrm{H}_{24} \mathrm{~N}_{2} \mathrm{O}_{4}{ }^{+},\left([\mathrm{M}]^{+}\right)$requires 500.1736 found 500.1739 .

\section{$N, N^{\prime}, N^{\prime}$ '-((((benzene-1,3,5-tricarbonyl)tris(benzene-4,1-diyl))tris(oxy))tris(benzene-4,1-diyl))tris(2,2,2- trifluoroacetamide) (TRI-EC) 6a}

DCM $(100 \mathrm{ml})$ was added to a conical flask with a magnetic stirrer and cooled in ice to $5^{\circ} \mathrm{C}$. Aluminium chloride $(5.11 \mathrm{~g}, 38.3 \mathrm{mmol})$ was added, with swirling, together with the DCM washings. Between each of the subsequent additions and washings, the mixture was cooled in ice to below room temperature with swirling. Next, 1, 3, 5- benzenetricarbonyl chloride (TRI) (1.52 g, $5.73 \mathrm{mmol}$ ) was added, followed by EC-F $(6.00 \mathrm{~g}, 21.3 \mathrm{mmol})$, including the DCM washings $(100 \mathrm{ml}$ total). The addition of EC-F caused the solution to turn green. The mixture was stirred at room temperature for 1.5 hours. After 5 minutes the solution became orange, then after a further 15 minutes a dark viscous liquid formed at the bottom of the flask. The resulting orange solution and dark orange viscous solid was poured into iced water, and was stirred at a moderate speed for 1 hour, resulting in a small amount of a white precipitate in the aqueous layer and an orange organic layer. This mixture was heated on a hotplate to remove the DCM. A green sticky solid was isolated by decanting the aqueous layer. This solid was dissolved in acetone $(100 \mathrm{ml})$ and decolourising charcoal added ( 1 g). After stirring for 10 minutes, the solution was filtered, yielding a pale brown solution. On evaporation of the acetone, a brown sticky solid remained. This solid was stirred in methanol (100 $\mathrm{ml})$, causing the precipitation of a white solid. The solid was isolated by filtration and dried in an air oven, yielding TRI-EC 6a as a pale grey solid (4.24 g, 74\%); mp $172.3{ }^{\circ} \mathrm{C}$; purity $97.82 \mathrm{~mol} \%$ (DSC); $v_{\max } / \mathrm{cm}^{-1}$ 3442 and $3302(\mathrm{NH}), 2395$ - 1925 (aromatic CH), 1702 (amide CO), 1655 (CO), 1591 (central ring stretch), $1559(\mathrm{NH}), 1497$ (central ring stretch), $1292(\mathrm{NH}), 1227$ (COC), 1157, 1003; $\delta_{\mathrm{H}}\left(400 \mathrm{MHz}, \mathrm{CDCl}_{3 \text { (TFA) }}\right) 7.09$ $(6 \mathrm{H}, \mathrm{d}, J 8.80, \mathrm{C}(6) H), 7.17$ (6H, d, $J 9.05, \mathrm{C}(9) H), 7.64(6 \mathrm{H}, \mathrm{d}, J 9.05, \mathrm{C}(10) H), 7.88(6 \mathrm{H}, \mathrm{d}, J 8.80, \mathrm{C}(5) H)$, $8.35(3 \mathrm{H}, \mathrm{s}, \mathrm{C}(1) H) ; \delta_{\mathrm{C}}\left(100 \mathrm{MHz}, \mathrm{CDCl}_{3 \text { (TFA) }}\right) 114.23$ and 117.08 (quartet partially visible) $\left(C \mathrm{~F}_{3}\right), 117.54$ $(C(6)), 121.26(C(9)), 123.13(C(10)), 130.21(C(11)), 131.31(C(4)), 133.26(C(5)), 134.27(C(1)), 138.21$ $(C(2)), 153.29(C(8)), 157$ quartet $(C F 3), 162.80(C(7)), 195.80(C(3)) ; \delta_{\mathrm{F}}\left(376 \mathrm{MHz}, \mathrm{CDCl}_{3(\mathrm{TFA})}\right)-75.66$ $\left(\mathrm{CF}_{3}\right)$; HRMS (TOF $\left.\mathrm{EI}^{+}\right) \mathrm{C}_{51} \mathrm{H}_{30} \mathrm{~F}_{9} \mathrm{~N}_{3} \mathrm{O}_{9}^{+}\left([\mathrm{M}]^{+}\right)$requires 999.1838 found 999.1856.

\section{Benzene-1,3,5-triyltris((4-(4-aminophenoxy)phenyl)methanone) (TRI-EC-D) 6b}


A portion of TRI-EC $6 \mathbf{6}(153 \mathrm{mg}, 0.153 \mathrm{mmol})$ was treated with deionised water $(25 \mathrm{ml})$ and IPA $(25 \mathrm{ml})$, and made up to $\mathrm{pH} 13$ with a single sodium hydroxide pellet, which caused TRI-EC to dissolve. The mixture was heated at $85{ }^{\circ} \mathrm{C}$ for 1.5 hours, during which time a yellow suspension was produced. The solid was isolated by filtration, washed with deionised water and dried in an air oven to yield TRI-EC-D $\mathbf{6 b}$ as a pale yellow solid (0.0771 g, $71 \%$ ); $\mathrm{mp} 167.4{ }^{\circ} \mathrm{C}$; purity $97.72 \mathrm{~mol} \%$ (DSC); $v_{\max } / \mathrm{cm}^{-1} 3456$ and $3366(\mathrm{NH}), 2150$ - 1820 (aromatic CH), 1702 (amide CO), 1651 (CO), 1593 and 1499 (central ring stretch), 1312 (CN), 1236 (COC), 1197, 1159 (COC), 1157, 1005; HRMS (TOF $\left.\mathrm{EI}^{+}\right) \mathrm{C}_{30} \mathrm{H}_{24} \mathrm{O}_{3}^{+}\left([\mathrm{M}]^{+}\right.$) requires 711.2369 found 711.2212 .

\section{5,5'-Oxybis(2-(4-phenoxyphenyl)isoindoline-1,3-dione) (EIEIE) $)^{17}$}

White solid; $\mathrm{mp} 293.4{ }^{\circ} \mathrm{C}\left(2^{\circ} \mathrm{C} / \mathrm{min}\right)\left(\right.$ lit. $\left.^{3} 292.2-293.8^{\circ} \mathrm{C}\right)$; purity $99.35 \mathrm{~mol} \%$ (DSC); $v_{\max } / \mathrm{cm}^{-1} 3062(\mathrm{CH})$, $3034(\mathrm{CH}), 2374-1703$ (Ar CH), 1604 (CO), 1589 (ring stretch), 1485 (ring stretch), 1267 (COC), 1234 $(\mathrm{CN}), 1024(\mathrm{CN}) ; \delta_{\mathrm{H}}\left(400 \mathrm{MHz}, \mathrm{CDCl}_{3 \text { (TFA) }}\right) 7.12(4 \mathrm{H}, \mathrm{d}, J$ 7.58, C(3)H), $7.14(4 \mathrm{H}, \mathrm{d}, J 9.05, \mathrm{C}(6) H), 7.22$ $(2 \mathrm{H}, \mathrm{t}, J 7.58, \mathrm{C}(1) H), 7.33(4 \mathrm{H}, \mathrm{d}, J 9.05, \mathrm{C}(7) H), 7.43(4 \mathrm{H}, \mathrm{t}, J 7.58, \mathrm{C}(2) H), 7.58$ (2H, dd, $J$ 8.07, 2.20, $\mathrm{C}(14) H), 7.65(2 \mathrm{H}, \mathrm{d}, J 2.20, \mathrm{C}(16) H), 8.10(2 \mathrm{H}, \mathrm{d}, J 8.31, \mathrm{C}(13) H) ; \delta_{\mathrm{C}}\left(100 \mathrm{MHz}, \mathrm{CDCl}_{3}(\mathrm{TFA})\right) 114.65$ $(C(16) \mathrm{H}), 118.79(C(6) \mathrm{H}), 119.85(C(3) \mathrm{H}), 124.41(C(1) \mathrm{H}), 124.75(C(11)), 125.53(C(14) \mathrm{H}), 126.75$ $(C(8)), 126.95(C(13) \mathrm{H}), 128.42(C(7) \mathrm{H}), 130.03(C(2) \mathrm{H}), 134.16(C(10)), 155.90(C(5)), 158.39(C(4))$, $161.57(C(15)), 168.05(C(9)), 168.31(C(12))$; HRMS (TOF EI $\left.{ }^{+}\right) \mathrm{C}_{40} \mathrm{H}_{24} \mathrm{~N}_{2} \mathrm{O}_{7}^{+}\left([\mathrm{M}]^{+}\right)$requires 644.1583 found 644.1472 .

\section{Synthesis and Characterisation of Polymers ${ }^{22,32,33}$}

The PEKKs were synthesised with monomer feeds as detailed in Table 2. A representative polymerisation procedure for amine end capped PEKK with 80:20 T:I ratio is as follows.

\begin{tabular}{|l|c|c|c|c|c|c|}
\hline Monomers & $\begin{array}{l}\text { Small } \\
\text { scale }\end{array}$ & $\begin{array}{c}\mathbf{1 0 0 : 0} \\
\text { PEKK }\end{array}$ & $\begin{array}{c}\mathbf{8 0 : 2 0} \\
\text { PEKK }\end{array}$ & $\begin{array}{c}\mathbf{6 0 : 4 0} \\
\text { PEKK }\end{array}$ & Imide & Branched \\
\hline EKKE & 9.75 & 266.00 & 265.99 & 265.98 & 140.02 & 265.04 \\
\hline TPC & 4.63 & 120.83 & 73.71 & 26.66 & 90.60 & 68.37 \\
\hline IPC & - & - & 47.10 & 94.17 & - & 45.68 \\
\hline Benzoic acid & 11.11 & 292.99 & 293.09 & 293.02 & 218.25 & 289.10 \\
\hline $\mathrm{AlCl}_{3}$ & 30.42 & 766.17 & 764.80 & 767.87 & 609.16 & 751.37 \\
\hline EC-F & 1.12 & 16.67 & 16.69 & 16.68 & 11.94 & 15.89 \\
\hline EIEIE & - & - & - & - & 82.21 & - \\
\hline TRI & - & - & - & - & - & 5.22 \\
\hline DCM & 125 & 3500 & 3500 & 3500 & 3500 & 3500 \\
\hline
\end{tabular}

To a five litre reaction flask equipped with a mechanical stirrer, having been purged with dry nitrogen, was added aluminium chloride $(764.80 \mathrm{~g}, 5.7297 \mathrm{~mol})$ along with dichloromethane $(250 \mathrm{ml})$. Stirring was maintained at $200 \mathrm{rpm}$. Having cooled the slurry to $-20{ }^{\circ} \mathrm{C}$, benzoic acid (293.0939.304 g, $\left.2.3982 \mathrm{~mol}\right)$ was slowly added so as not to raise the temperature of the slurry above $-10^{\circ} \mathrm{C}$ and to minimise any splashing up the walls of the reactor. After cooling back to $-20^{\circ} \mathrm{C}$, the combined isophthaloyl chloride $(47.10 \mathrm{~g}, 0.23199$ mol) and terephthaloyl chloride $(73.71 \mathrm{~g}, 0.36307 \mathrm{~mol})$ was added to the slurry along with a further $100 \mathrm{ml}$

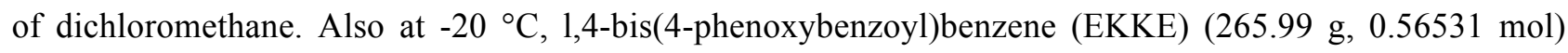


was added with a further $100 \mathrm{ml}$ of dichloromethane, which was accompanied by a colour change from yellow to orange. The remaining DCM was added, retaining a small amount $(15-20 \mathrm{ml})$ for the addition of the EC-F. The stirrer speed was increased to $500 \mathrm{rpm}$. During this heating, the EC-F (16.69 g, $59.346 \mathrm{mmol})$, diluted in the remaining DCM, was added. The formation of particles was observed after approximately 15 minutes. The vessel was stirred at a constant rate of $500 \mathrm{rpm}$ and maintained at $20^{\circ} \mathrm{C}$ for four hours.

The orange complexed polymer was filtered and was added to iced water in portions with stirring, causing it to decomplex and turn white. During decomplexation, the mixture did not exceed $5{ }^{\circ} \mathrm{C}$. The beaker was stirred occasionally over approximately ten minutes until the majority of the polymer had turned white, with some orange parts remaining. The beaker was left to stand overnight and until workup to achieve full decomplexation. Having transferred the polymer to a suitable vessel, the vessel was heated and the dichloromethane distilled off. The polymer was subsequently subjected to a workup procedure of sequential washings, consisting of hot water, aqueous acid and base stages. Polymers were dried at $80{ }^{\circ} \mathrm{C}$ for 48 hours, then at $200^{\circ} \mathrm{C}$ (up to $250^{\circ} \mathrm{C}$ ) under vacuum overnight, and then characterised as indicated in the main text.

\section{References}

1. $\quad$ K. P. Unnikrishnan and E. T. Thachil, Des. Monomers Polym., 2006, 9, 129-152.

2. $\quad$ P. Mohan, Polym.-Plast. Technol. Eng., 2013, 52, 107-125.

3. N. R. Paluvai, S. Mohanty and S. K. Nayak, Polym.-Plast. Technol. Eng., 2014, 53, 1723-1758.

4. J. N. Sultan and F. J. McGarry, Polym. Eng. Sci., 1973, 13, 29-34.

5. $\quad$ R. J. Young and P. W. R. Beaumont, J. Mat. Sci., 1977, 12, 684-692.

6. $\quad$ Y. Huang and A. J. Kinloch, Polymer, 1992, 33, 1330-1332.

7. C. B. Bucknall and A. H. Gilbert, Polymer, 1989, 30, 213-217.

8. M. R. Bonneau, J. D. Boyd, G. T. Emmerson, S. D. Lucas, S. J. Howard and S. D. Jacobs, 2012, US Patent 8,268,926 B262.

9. J. A. Cecere, J. L. Hedrick and J. E. McGrath, in Materials Sciences for the Future. 31st International SAMPE Symposium and Exhibition, eds. J. L. Bauer and R. Dunaetz, 1986, pp. 580588.

10. R. D. Brooker, A. J. Kinloch and A. C. Taylor, J. Adhes., 2010, 86, 726-741.

11. C. B. Bucknall and I. K. Partridge, Polymer, 1983, 24, 639-644.

12. J. F. Pratte, R. K. Maskell, I. D. H. Towle and K. J. Smith, 2015, US Patent 2015/0337082_A1.

13. G. S. Bennett and R. J. Farris, J. Polym. Sci., Part A: Polym. Chem., 1994, 32, 73-87.

14. G. C. Corfield, G. W. Wheatley and D. G. Parker, J. Polym. Sci., Part A: Polym. Chem., 1992, 30, 845-849.

15. M. Matzner and D. M. Papuga, 1990, US Patent 4,959,424.

16. K. J. Smith, I. D. H. Towle and M. G. Moloney, RSC Advances, 2016, 6, 13809-13819.

17. P. J. Horner and R. H. Whiteley, J. Mater. Chem., 1991, 1, 271-280.

18. Peter G. M. Wuts, Theodora W. Greene, Greene's Protective Groups in Organic Synthesis, Fourth Edition, 4th ed., 1991, Wiley, New York.

19. D. J. M. Daoust, J. J. Devaux, R. M. Legras, J. P. Mercier and E. Nield, 1987, US Patent 4,657,990.

20. I. D. H. Towle, 1989, US Patent 4,841,013.

21. P. M. Hergenrother, N. T. Wakelyn and S. J. Havens, J. Polym. Sci., Part A: Polym. Chem., 1987, 25, 1093-1103.

22. I. D. H. Towle, 2011, US Patent 9,023,468.

23. K. J. Smith and I. D. H. Towle, Ketonex Limited, Br., 2014, GB20140009126 20140522.

24. D. Kemmish, Update on the Technology and Applications of Polyaryletherketones, Smithers Rapra, Shawbury, 2010.

25. J. N. Hay and D. J. Kemmish, Polymer, 1987, 28, 2047-2051. 
26. J. Coates, "Interpretation of Infrared Spectra, A Practical Approach" in Encyclopedia of Analytical Chemistry, 2006, John Wiley \& Sons, Ltd.

27. A. C. Henry, T. J. Tutt, M. Galloway, Y. Y. Davidson, C. S. McWhorter, S. A. Soper and R. L. McCarley, Anal. Chem., 2000, 72, 5331-5337.

28. D. R. Corbin and E. Kumpinsky, 1990, US Patent 4,918,237.

29. Z. J. Liu and R. C. Larock, J. Org. Chem., 2006, 71, 3198-3209.

30. R. C. Weast, Handbook of Chemistry and Physics, 1983, CRC Press, Inc., 64 edn.

31. J. F. Pratte, R. K. Maskell, J.M. Griffin and J. A. Elder, 2015, US Patent 2015/0337183_A1.

32. J. F. Pratte, R. K. Maskell, I. D. H. Towle and K. J. Smith, 2015, WO2015179587_A1.

33. I. D. H. Towle and K. J. Smith, 2015, WO2015177549_A1. 